\title{
A serological study of exposure to arthropod-borne pathogens in dogs from northeastern Spain
}

\author{
Laia SolANO-GALLEGO ${ }^{\mathrm{a}}$, Joan Llull ${ }^{\mathrm{b}}$, Montsant OSSO $^{\mathrm{c}}$, \\ Barbara HEGARTY ${ }^{\mathrm{a}}$, Edward BREITSCHWERDT ${ }^{\mathrm{a} *}$ \\ a Department of Clinical Sciences, College of Veterinary Medicine, North Carolina State University, \\ 4700 Hillsborough Street, Raleigh, NC 27606, North Carolina, USA \\ ${ }^{b}$ Hospital Mon Veterinari, Manacor, Mallorca, Spain \\ c Mediterrani Veterinaris, Reus, Tarragona, Spain
}

(Received 11 April 2005; accepted 20 September 2005)

\begin{abstract}
There is limited information regarding the prevalence of many vector borne pathogens in Europe and especially in Spanish dogs. We investigated 206 sick and 260 clinically healthy dogs from three different regions in northeastern Spain for antibodies to Rickettsia conorii (Rc), Ehrlichia canis (Ec), Anaplasma phagocytophilum (Ap), Bartonella henselae (Bh), Bartonella vinsonii subsp. berkhoffii $(B v b)$, Leishmania infantum $(L i)$ and Borrelia burgdorferi $(B b)$ and for antigen of Dirofilaria immitis (Di). Total prevalences were the following: Rc (56.4\%), Li (30\%), Ec (16.7\%), $B h(16.8 \%), A p(11.5 \%), B v b(1.07 \%), D i(0.6 \%)$ and $B b(0.6 \%)$. Seroprevalences for $R c, E c, A p$, $B h$, and $B v b$ and $B b$ and $D i$ antigens were similar among the three different study sites. The $E c$ seroprevalence, as determined by Snap 3DX, was statistically lower in dogs from Mallorca ( $0 \%)$ than Tarragona $(16 \%)$ and Barcelona $(5 \%)(P<0.0001)$. Detection of $R c$ antibodies was associated with seroreactivity to $E c$ and $A p$ antigens $(P=0.018$ and $P=0.002$, respectively). IFA $E c$ antibodies were associated with $A p$ seroreactivity $(P<0.0001)$. There was no association between the clinical status, sex, time of the year when samples were collected, life-style or exposure to fleas or ticks and a positive test result for $E c, B h, B v b$, or $B b$ antibodies or $D i$ antigens. $L i$ seroreactivity was associated with illness and living outdoors $(P<0.0001, P=0.029$; respectively), $R c$ seroreactivity with the male gender $(P=0.028)$ and $A p$ seroreactivity with living outdoors $(P=0.045)$. This study indicates that exposure to $R c, L i, E c$ or related Ehrlichia spp., Bh and $A p$ or a related spp., is common whereas $D i, B b$ and $B v b$ is uncommon among dogs from the Mediterranean basin. We also provide serological data that suggests the existence of a novel Ehrlichia species on Mallorca island.
\end{abstract}

rickettsial pathogens / dogs / Spain

\section{INTRODUCTION}

The medical and veterinary importance of vector borne diseases in dogs results from the transmission of a wide variety of infectious agents including Leishmania spp., Babesia spp., Ehrlichia spp., Anaplasma spp., Rickettsia spp., Borrelia spp.,
Bartonella spp., Dirofilaria spp. and others. Vector-borne infections are increasingly recognized as the cause of severe clinical illness in dogs such as leishmaniasis, ehrlichiosis, babesiosis, anaplasmosis and bartonellosis. Furthermore, subclinically infected dogs can transport infected arthropods (fleas and ticks) into close proximity to people

*Corresponding author: ed_breitschwerdt@ncsu.edu 
or serve as a reservoir for human vectortransmitted infectious agents such as Leishmania spp. [36].

In Europe, there is little information regarding the prevalence of many vector borne diseases in dogs or the comparative seroprevalence for various organisms in specific geographical areas of Europe [42]. With regards to the dog, most of the vector borne disease studies in Europe have emphasized canine leishmaniosis, with over 106 studies cited on a 2004 Medline search. There were thirty-four studies, found on Medline, that investigated canine borreliosis, 31 studies investigating canine ehrlichiosis (which includes $E$. equi, now designated $A$. phagocytophilum $(A p)$ ), 26 studies investigating $R$. conorii $(R c), 23$ studies investigating $D$. immitis $(D i)$ and three studies that consider canine bartonellosis.

Because of intense exposure to arthropod vectors, dogs can be simultaneously or sequentially exposed to a spectrum of vector borne organisms. Some vector-borne pathogens such as $L i$ have been extensively studied in dogs from Europe, whereas other pathogens such as $B v b$ have been less extensively studied. Since the dog can serve as an excellent sentinel for the detection and characterization of zoonotic vector borne infections, regional exposure patterns can be readily established through epidemiological investigations using dog sera. In order to further characterize patterns of exposure to vector-borne pathogens in dogs from northeastern Spain, we investigated the prevalence of exposure to eight vectorborne pathogens L. infantum ( $\mathrm{Li}$ ), Borrelia burgdorferi (Bb), E. canis (Ec), Ap, Rc, Di, $B$. henselae $(B h)$ and $B$. vinsonii subsp. berkofii $(B v b)$ in a convenience sample of clinically healthy and sick dogs.

\section{MATERIALS AND METHODS}

\subsection{Dogs}

Four hundred sixty-six dogs from northeastern Spain were studied. Blood samples were obtained from three different regions: Mallorca island ( $n=300)$, Tarragona ( $n=$ 116) and Barcelona $(n=50)$. Sera from Mallorca dogs were collected between October 2001 and July 2002 at a private veterinary hospital located in Manacor (Mallorca Island) (latitude $=39^{\circ} 35^{\prime} \mathrm{N}$ and longitude $=3^{\circ} 12^{\prime} \mathrm{E}$ ). Sera from Tarragona and Barcelona dogs were collected between December 2001 and May 2002 at a private veterinary hospital located in Reus (Tarragona, Catalonia) (latitude $=41^{\circ} 09^{\prime} \mathrm{N}$ and longitude $=001^{\circ} 07^{\prime} \mathrm{E}$ ) and at the Veterinary Teaching Hospital of Universitat Autònoma de Barcelona located in Cerdanyola (Barcelona, Catalonia) (latitude $=41^{\circ} 24^{\prime} \mathrm{N}$ and longitude $=2^{\circ} 09^{\prime} \mathrm{E}$ ), respectively. All care and diagnostics were done with the owner's explicit permission and in conjunction with local veterinarians.

\subsection{Questionnaires}

Questionnaires were administered to veterinarians working in the three different veterinarian hospitals. Information collected on the questionnaires included the period of sample collection, age, sex, breed, type of housing (indoor versus outdoor), flea and tick-exposure, clinical status (sick versus healthy) and clinicopathological findings. Dogs were considered sick if at least one sign of illness was reported. Clinically healthy dogs were those with no clinical signs or historical abnormalities. Clinical signs were divided into the following categories: loss of weight, fever, asthenia, epistaxis, pale mucous membranes, lymphadenomegaly, lameness, and cutaneous, mucocutaneous, ocular, cardiopulmonary, gastrointestinal, neurological, urinary and reproductive signs. Clinicopathological findings were divided into the following categories in the questionnaires: hypergammaglobulinemia, hypercreatinemia, anemia, thrombocytopenia, leukopenia and leukocytosis. Year period was divided into two categories (October-March and AprilJuly). 


\subsection{Serologic testing}

\subsubsection{Detection of IgG antibodies to Bh, Bvb, Rc, Ec and Ap by immunofluorescence assay (IFA)}

Bartonella henselae, Bvb NCSU 93CO1 and Israeli-2 strain of $R c$ were cultivated in Vero cells and harvested when cells were more than $80 \%$ infected ( 2 to 9 days postinoculation). Ehrlichia canis (NCSU, DJ strain) was grown as described previously by in vitro propagation in the DH82-cell line [40]. Anaplasma phagocytophilum (strain 96HE158) was grown as described previously by in vitro propagation in the HL60 [14] cell line. Antigen for the IFA was prepared as previously described $[14,40]$.

Three twofold serial dilutions of sera $(1: 16,1: 32,1: 64)$ in PBS $0.05 \%$ Tween 20 (T)- $0.5 \%$ dried skimmed milk (M)- $1 \%$ goat sera $(\mathrm{G})$ were made in microtiter plates. Ten microliters of each dilution were applied per well, and the slides were incubated at $37^{\circ} \mathrm{C}$ for $30 \mathrm{~min}$, washed in PBS with agitation for $30 \mathrm{~min}$ and air-dried. Fluorescein conjugated goat anti-dog immunoglobulin (whole molecule immunoglobulin G; Cappel, Organon Teknika Corp., Durham, NC, USA) was diluted 1:100 in PBSTMG, filtered with $0.22 \mu \mathrm{m}$ filter to remove precipitants and applied to each well. The slides were incubated for $30 \mathrm{~min}$ at $37{ }^{\circ} \mathrm{C}$ and washed again in PBST with agitation for $30 \mathrm{~min}$, rinsed with deionized water, air dried, cover slipped using mounting medium (90\% glycerol and 10\% PBS, $\mathrm{pH} 9.0$ ) and viewed with a fluorescence microscope (magnification, $\times 400$ ). Ehrlichia canis and Ap IFA were performed on each serum sample as described above. The only modification was that the slides, after the last wash with PBST, were counter stained with Eriochrome black before the final rinse in deionized water. Samples with an IFA titer $>1: 32$ were retested with serial dilutions from 1:16 to $1: 8192$. End point titers were determined as the last dilution at which brightly stained organisms could be detected on a fluorescence microscope with exciter and barrier filters.

For all antigens, a reactive serum was defined as a titer of $\geq 1: 64$. Sera from dogs experimentally infected with $B h$ (titer 1:512) (kindly provided by Dr Bruno Chomel, University of California, Davis, USA, unpublished results), $B v b$ (titer $1: 1024), R c$ (titer 1:1024), Ec (titer 1:4096) and $A p$ (titer 1:1024) were used as positive controls and a nonreactive serum from a specific pathogen free (SPF) dog was used as a negative control for all IFA testing.

\subsubsection{Detection of IgG antibodies to Li by enzyme linked immunoabsorbent assay (ELISA)}

An ELISA was performed as previously described [37]. Briefly, microtitre plates (Costar, 96 well flat bottom, polystyrene microplates/\#3590) were coated with $20 \mu \mathrm{g} \cdot \mathrm{mL}^{-1}$ of $\mathrm{Li}$ antigen and incubated overnight at $4{ }^{\circ} \mathrm{C}$. One hundred microlitres per well of dog sera, diluted 1:400 in PBS$0.05 \%$ Tween $20-1 \%$ dried skimmed milk, were incubated for $1 \mathrm{~h}$ at $37^{\circ} \mathrm{C}$. After washing, protein $\mathrm{A}(0.06 \mu \mathrm{g} / \mathrm{mL})$ conjugated to horseradish peroxidase (Sigma) was added. This conjugate was incubated for $1 \mathrm{~h}$ at $37^{\circ} \mathrm{C}$, and then the plates were rewashed. The substrate solution (ortho-phenylenediamine, $0.4 \mu \mathrm{g} \cdot \mathrm{mL}^{-1}$, Sigma) and $\mathrm{H}_{2} \mathrm{O}_{2}$ $\left(0.4 \mu \mathrm{g} \cdot \mathrm{mL}^{-1}\right)$ in $0.1 \mathrm{M}$ of phosphate/citrate buffer pH 5.0 was added at $200 \mu \mathrm{L} /$ well and developed for $20 \mathrm{~min}$ at $24{ }^{\circ} \mathrm{C}$. The reaction was stopped with $50 \mu \mathrm{L}$ of $3 \mathrm{M} \mathrm{H}_{2} \mathrm{SO}_{4}$. Absorbance values were read at $492 \mathrm{~nm}$ in an automatic microELISA reader (Anthos 2001, Anthos Labtec Instruments, Ges.m.b.h., Austria). The result was quantified as units (U) related to a positive serum used as a calibrator and arbitrarily set at $100 \mathrm{U}$. The cutoff was established at $35 \mathrm{U}$ (mean $+4 \mathrm{SD}$ of 32 dogs from non-endemic areas). The results below this cutoff were considered uncertain if higher than $23 \mathrm{U}$ (mean + 2 SD), and negative if less than $23 \mathrm{U}$. 


\subsubsection{Detection of Di antigen, Ec antibodies and $\mathrm{Bb}$ antibodies}

Four hundred sixty dog serum samples were tested with a commercial ELISA assay kit (Canine SNAP ${ }^{\circledR} 3$ Dx $^{\mathrm{TM}}$ Test; IDEXX Laboratories, USA) which detects $D i$ antigen, $E c$ antibodies (P30 and P30-1 outer membrane proteins) and $B b$ antibodies (C-6 peptide).

\subsection{Statistical analysis}

For univariate analysis, non-parametric tests (chi-square) were used to test for associations between proportions and putative explanatory factors. When testing for associations with $E c$ seroreactivity, the $E c$ results from IFA testing were used exclusively. The differences among groups were analyzed by the unpaired Student $\mathrm{T}$ test. The differences were considered significant if the $P$-value was $<0.05$.

\section{RESULTS}

\subsection{Dogs}

Demographic information was not available for all cases. Amongst the Mallorca dogs, 83 were sick dogs with various illnesses and 146 clinically healthy dogs, 202 lived outdoors and 39 dogs lived indoors. One hundred forty-five dogs were male and 130 dogs were female. Age was known for $274 \operatorname{dogs}$ with a mean \pm SD of $6.2 \pm$ 3.8 years. Ages ranged from 5 months to 19 years. Various breeds were represented and 105 dogs were of mixed breeding. There was no association between clinical status, sex, period of the year, life-style or exposure to fleas or ticks and positive test results for $E c, B h, B v b, D i$ or $B b$ antigens (Tab. I). There was a positive association between the detection of $L i$ antibodies and illness $(P<0.000001)$; between $R c$ antibodies and male dogs $(P=0.028)$, between $L i$ or $A p$ antibodies and living outdoors ( $P=$ $0.029, P=0.045$; respectively).
Among the Tarragona dogs, 98 were sick dogs and nine clinically healthy dogs. Sixty-one dogs lived outdoors and $45 \mathrm{dogs}$ lived indoors. Seventy-five dogs were male and 40 dogs were female. The age was known for 92 dogs with a mean \pm SD of $5.6 \pm 3.6$ years. Ages ranged from 6 months to 15 years. Various breeds were represented and 35 dogs were of mixed breeding.

Amongst the Barcelona dogs, 27 were sick dogs and 20 clinically healthy dogs. Twenty-one dogs lived outdoors and one dog lived indoors. Twenty-four dogs were male and 17 dogs were female. The age was known for $34 \mathrm{dogs}$ with a mean \pm SD of $4.6 \pm$ 3.4 years. Ages ranged from 6 months to 14 years. Various breeds were represented and 12 dogs were of mixed breeding.

There was no association between clinical status, sex, period of the year, life-style or exposure to fleas or ticks and positive test results for $L i, R c, E c, B h, B v b, D i$ or $B b$ antigens in dogs from Tarragona or Barcelona.

\subsection{Serology for arthropod borne pathogens}

The total and regional seroprevalence to various test antigens and the prevalence to the $D i$ antigen are shown in Tables II and III. Seventy-six dogs (16.3\%) were negative for all eight diagnostic tests and no dog was positive for all eight organisms. The $R c, E c, A p$, and $B h$ seroprevalences determined by IFA were similar among the three different regions with the exception of $B h$ seroprevalence that was not studied in Tarragona. The prevalences of $D i$ antigen, $B b$ and $B v b$ antibodies, all of which were rarely detected ( $n \leq 5 \mathrm{dogs}$ each), were also similar among the three different regions. In contrast, the Ec seroprevalence as determined by the Snap 3DX test (Tab. III) was statistically much lower in Mallorca dogs than for Tarragona and Barcelona dogs $(P<$ $0.000001)$. In addition, the geometric mean of Ec IFA was statistically much lower in Mallorca dogs than in Tarragona $(P<0.000001)$ or Barcelona $(P=0.029)$ 


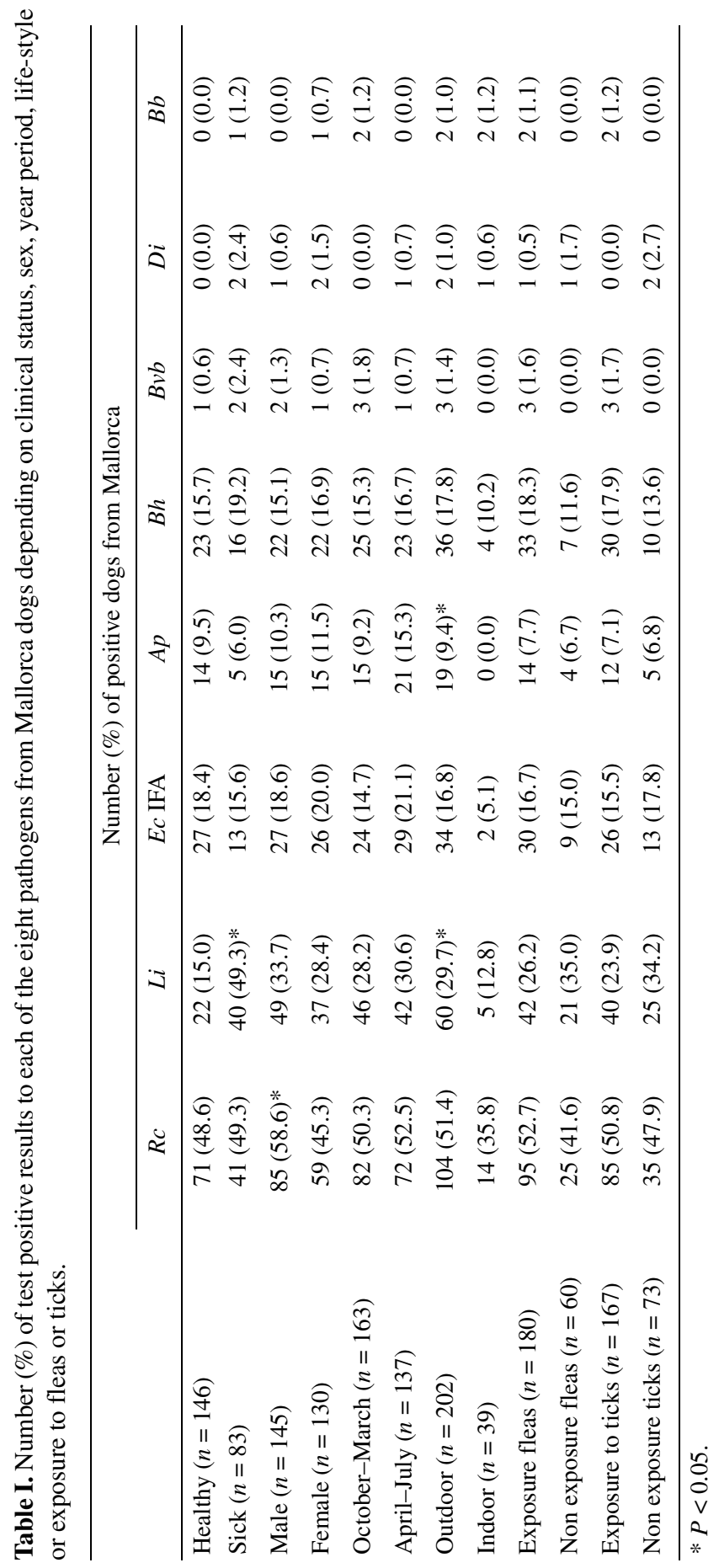




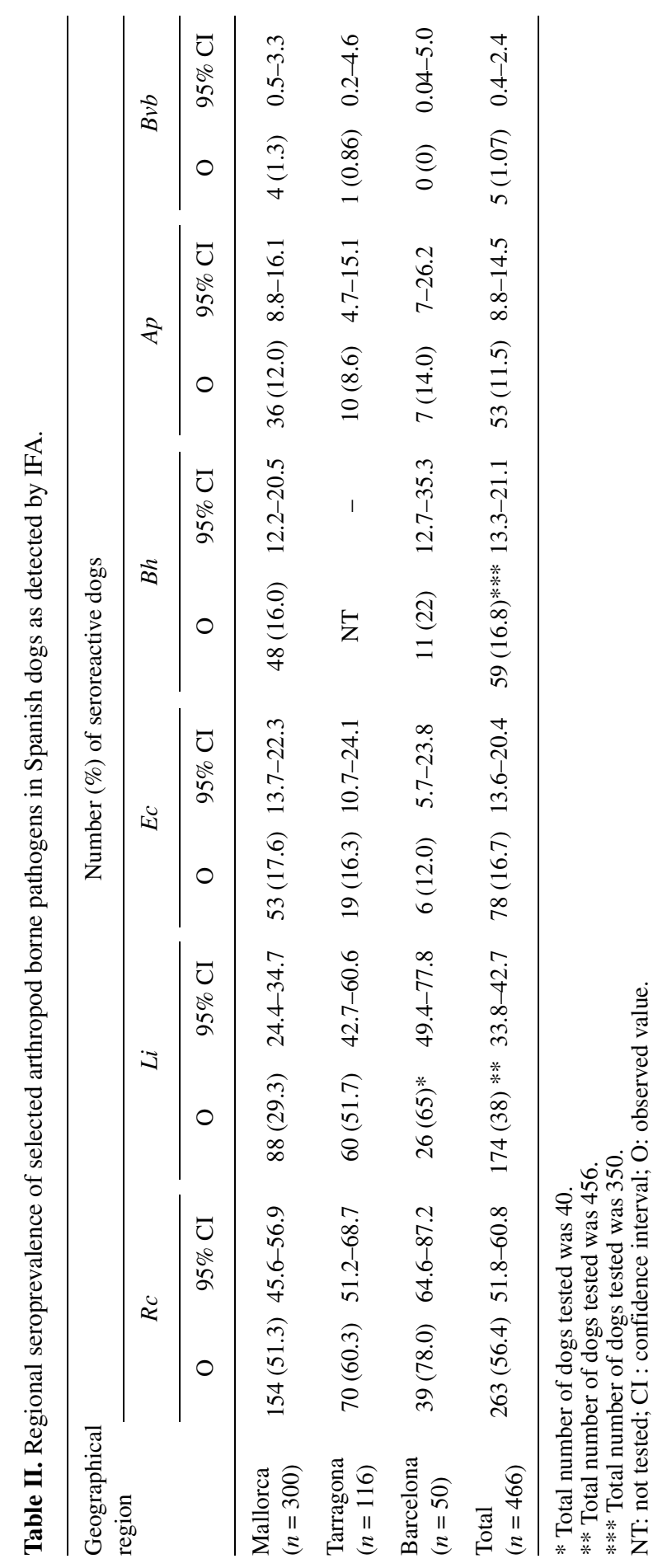


Table III. Regional seroprevalence of selected arthropod borne pathogens as detected by a commercial screening test.

\begin{tabular}{|c|c|c|c|c|c|c|}
\hline \multirow[t]{3}{*}{ Geographical origin* } & \multicolumn{6}{|c|}{ Number (\%) of positive dogs by Snap test } \\
\hline & \multicolumn{2}{|c|}{$D i$ ag } & \multicolumn{2}{|c|}{$B b$ ab } & \multicolumn{2}{|c|}{$E c \mathrm{ab}$} \\
\hline & $\mathrm{O}$ & $95 \% \mathrm{CI}$ & $\mathrm{O}$ & $95 \% \mathrm{CI}$ & $\mathrm{O}$ & $95 \% \mathrm{CI}$ \\
\hline Mallorca $(n=299)$ & $1(0.3)$ & $0.08-1.0$ & $2(0.66)$ & $0.2-2.3$ & $0(0)$ & $0.084-1.2$ \\
\hline Tarragona $(n=112)$ & $1(0.85)$ & $0.2-4.8$ & $0(0)$ & $0.02-3.2$ & $16(13.6)$ & 9-21.9 \\
\hline Barcelona $(n=49)$ & $1(2.0)$ & $0.4-10$ & $1(2.0)$ & $0.48-10.6$ & $5(10.2)$ & $4.5-21.8$ \\
\hline Total $(n=460)$ & $3(0.6)$ & $0.2-1.0$ & $3(0.6)$ & $0.2-1.8$ & $21(4.5)$ & $3-6.8$ \\
\hline
\end{tabular}

* One dog from Mallorca, four dogs from Tarragona and one dog from Barcelona were not tested for these pathogens.

CI: confidence interval; O: observed value.

dogs. The seroprevalence of $L i$ was statistically much greater in Tarragona dogs than in Mallorca dogs $(P=0.000004)$. Some clinicopathological findings were statistically associated with seroreactivity to some antigens. Seroreactivity to $L i$ antigens was associated with hypergammaglobulinemia, hypercreatinemia and anemia $(P<0.000001$, $P=0.0028, P=0.000025$; respectively). Anemia was also associated with seroreactivity to $R c$ antigens $(P=0.035)$.

\subsubsection{Mallorca dogs}

Rickettsia conorii titers ranged from 1:64 to 1:4096 with a geometric mean titer of 1:438. Ehrlichia canis titers ranged from 1:64 to $1: 2048$ with a geometric mean titer of $1: 201$. In contrast to the IFA results, serum $E c$-specific IgG antibodies were not detected by the Snap 3DX test. Poor agreement was found between $E c$ IFA and $E c$ Snap 3DX tests (Kappa $<0.00001)$. Anaplasma phagocytophilum titers ranged from 1:64 to 1:4096 with a geometric mean titer of 1:251. Twenty-five dogs were seroreactive by IFA to both $E c$ and $A p$ antigens. Sera from 28 dogs were reactive to only $E c$ antigens and $11 \mathrm{dogs}$ were reactive to only $A p$ antigens. Fifteen out of 25 dogs had a higher $A p$ titer than $E c$ titer. Five out of 25 dogs had the same titer to both organisms and five out of $25 \mathrm{dogs}$ had a higher anti- body titer to $E c$ antigens as compared to $A p$ antigens. The results are shown in Table IV.

Bartonella henselae titers ranged from 1:64 to $1: 1024$ with a geometric mean titer of 1:141. Serum $B v b$ IgG antibodies ranged from $1: 64$ to $1: 1024$ with a geometric mean titer of $1: 128$. Two out of four dogs seroreactive to $B v b(n=2)$ were concurrently seroreactive to Bh. Dirofilaria immitis antigens were detected in $0.3 \%$ of the dogs and serum $B b$ C6 peptide antibodies were detected in $0.66 \%$ of the dogs. Serum $\mathrm{Li}^{-}$ specific IgG antibodies were detected in $29.2 \%$ of the dogs. The mean $\pm \mathrm{SD}$ of ELISA units was $148 \pm 85$.

The presence of $R c$ antibodies was associated with being seroreactive to $E c$ and $A p$ antigens $(P=0.018$ and $P=0.002$; respectively). Moreover, the detection of $E c$ antibodies was associated with seroreactivity to Ap antigens $(P<0.000001)$.

\subsubsection{Tarragona dogs}

Rickettsia conorii titers ranged from 1:64 to 1:4096 with a geometric mean titer of 1:382. Ehrlichia canis titers ranged from 1:64 to $1: 8192$ with a geometric mean titer of 1:2278. Anaplasma phagocytophilum titers ranged from 1:1024 to $1: 8192$ with a geometric mean titer of 1:3649. Ten dogs were IFA seroreactive to both $E c$ and $A p$ 
Table IV. Comparison of $E c, A p$ reciprocal titer IFA and $E c$ SNAP $3 D^{*}$ test results from $E c$ IFA seroreactive dogs from Mallorca.

\begin{tabular}{lcccccccc}
\hline Dog ID & IFA $E c$ & IFA $A p$ & Dog ID & IFA $E c$ & IFA $A p$ & Dog ID & IFA $E c$ & IFA $A p$ \\
\hline J252 & 2048 & 1024 & J262 & 256 & $<16$ & J238 & 64 & 128 \\
J336 & 1024 & 2048 & J269 & 256 & $<16$ & J172 & 64 & 128 \\
J264 & 1024 & $<16$ & J249 & 256 & $<16$ & J132 & 64 & 128 \\
J9 & 512 & 2048 & J167 & 256 & $<16$ & J220 & 64 & 64 \\
J334 & 512 & 1024 & J265 & 128 & 4096 & J68 & 64 & 64 \\
J314 & 512 & 1024 & J311 & 128 & 1024 & J178 & 64 & $<16$ \\
J313 & 512 & 256 & J147 & 128 & 256 & J219 & 64 & $<16$ \\
J305 & 512 & 256 & J340 & 128 & 256 & J76 & 64 & $<16$ \\
J69 & 512 & 32 & J182 & 128 & 128 & J236 & 64 & $<16$ \\
J73 & 512 & $<16$ & J75 & 128 & 32 & J89 & 64 & $<16$ \\
J248 & 512 & $<16$ & J116 & 128 & 32 & J152 & 64 & $<16$ \\
J62 & 256 & 2048 & J270 & 128 & $<16$ & J12 & 64 & $<16$ \\
J146 & 256 & 512 & J165 & 128 & $<16$ & J32 & 64 & $<16$ \\
J341 & 256 & 256 & J74 & 128 & $<16$ & J241 & 64 & $<16$ \\
J335 & 256 & 256 & J131 & 128 & $<16$ & J243 & 64 & $<16$ \\
J324 & 256 & 64 & J137 & 128 & $<16$ & & & \\
J129 & 256 & 64 & J258 & 128 & $<16$ & & & \\
J319 & 256 & 16 & J260 & 64 & 256 & & & \\
J266 & 256 & $<16$ & J345 & 64 & 256 & & & \\
\hline
\end{tabular}

* All Ec SNAP 3DX tests were negative.

antigens. Nine dogs were only seroreactive to $E c$ by IFA. No dog was seroreactive to only $A p$. Four out of ten dogs had a higher $E c$ titer than $A p$ titer. Five out of ten dogs had the same titer to both organisms and one out of ten dogs had a higher $A p$ titer than $E c$ titer. In contrast to the results obtained from Mallorca dogs, the Tarragona results, shown in Table V, found excellent agreement between $E c$ IFA and Ec Snap 3DX tests $($ Kappa $=0.898)$.

The only dog (MO91) seroreactive to $B v b$ antigens had a titer of 1:64. Dirofilaria immitis antigens were detected in $0.85 \%$ of the dogs and serum $B b$ C6 peptide antibodies were not detected in any dog from Tarragona. Serum $L i$-specific $\mathrm{IgG}$ antibodies were detected in $55.7 \%$ of the dogs. The mean \pm SD of ELISA units was $169 \pm 124$.
The presence of $R c$ antibodies was associated with $E c$ seroreactivity $(P=0.0098)$. The detection of $E c$ antibodies was also associated with $A p$ seroreactivity $(P<0.000001)$.

\subsubsection{Barcelona dogs}

Rickettsia conorii titers ranged from 1:64 to $1: 4096$ with a geometric mean titer of $1: 182$. Ehrlichia canis titers ranged from 1:64 to $1: 8192$ with a geometric mean titer of 1:322. Anaplasma phagocytophilum titers ranged from 1:1024 to 1:8192 with a geometric mean titer of 1:3649. Four dogs were positive by IFA to both $E c$ and $A p$ antigens. The results are shown in Table VI. Two dogs were only seroreactive to $E c$ by IFA. Three dogs were only seroreactive to $A p$. Two out of four dogs had a higher $A p$ 
Table V. Comparison of $E c, A p$ reciprocal titer of IFA and $E c$ SNAP 3DX from $E c$ IFA seroreactive dogs from Tarragona.

\begin{tabular}{cccc}
\hline Dog ID & IFA $E c$ & Snap $E c$ & IFA $A p$ \\
\hline MO91 & 8192 & + & 8192 \\
MO61 & 8192 & + & 8192 \\
MO8 & 8192 & + & 4096 \\
MO19 & 8192 & + & 4096 \\
MO73 & 8192 & + & 4096 \\
MO38 & 8192 & + & 2048 \\
MO64 & 8192 & + & 32 \\
MO122 & 4096 & + & 4096 \\
MO21 & 4096 & + & 32 \\
MO22 & 4096 & + & 32 \\
MO33 & 4096 & + & 32 \\
MO75 & 4096 & + & 32 \\
MO70 & 2048 & + & 2048 \\
MO81 & 2048 & + & 2048 \\
MO7 & 2048 & + & 32 \\
MO1 & 256 & - & 1024 \\
MO105 & 64 & + & 32 \\
MO66 & 64 & - & 32 \\
\hline
\end{tabular}

titer than $E c$ titer. Two out of four dogs had the same titer to both organisms. Good agreement was found between $E c$ IFA and Ec Snap 3DX tests, similar to the results from Tarragona (Kappa $=0.693)$.

Bartonella henselae titers ranged from 1:64 to $1: 256$ with a geometric mean titer \pm SD of 1:97 $\pm 1: 83$. Dirofilaria immitis antigens were detected in $2 \%$ of the dogs and serum $B b$ C6 peptide antibodies were detected in $2 \%$ of the dogs. Serum $\mathrm{Li}$ IgG antibodies were detected in $65 \%$ of the dogs. The mean \pm SD of ELISA units was $147.90 \pm 201$.

As was the case for Mallorca and Tarragona dogs, the detection of $E c$ antibodies was associated with $A p$ seroreactivity ( $P=$ 0.002).
Table VI. Comparison of $E c$, $A p$ reciprocal titer of IFA and $E c$ SNAP 3DX from $E c$ IFA seroreactive dogs from Barcelona.

\begin{tabular}{lccc}
\hline Dog ID & IFA Ec & Snap Ec & IFA $A p$ \\
\hline HCV 66 & 8192 & + & 8192 \\
HCV 107 & 8192 & + & 8192 \\
HCV 2 & 8192 & + & $<16$ \\
HCV 13 & 2048 & + & 4096 \\
HCV 129 & 256 & - & 4096 \\
HCV 106 & 64 & - & $<16$ \\
HCV 11 & 32 & - & 4096 \\
HCV 108 & $<16$ & - & 512 \\
HCV 132 & $<16$ & - & 64 \\
\hline
\end{tabular}

\section{DISCUSSION}

Dogs from all three locations had a very high prevalence $(56.4 \%)$ of $R c$ antibodies. Previous studies carried out in Spain described canine $R c$ seroprevalences of $26 \%$ [35] and 36.8\% [8]. We also report for the first time the detection of $R c$ antibodies in dogs from two geographical areas of northeastern Spain (Tarragona and Mallorca Island) where no previous studies have been conducted in dogs or humans. Rickettsia conorii is transmitted in the Mediterranean basin by the brown dog tick Rhipicephalus sanguineus. The $R c$ infection rate in $R$. sanguineus ticks in Sicily is $19.7 \%$ [41] and in Israel 7.3\% [16]. The high rates of $R c$ infection of $R$. sanguineus are in agreement with the high seroprevalences found in this and other studies in dogs living in the Mediterranean basin, where $R$. sanguineus is the predominant tick infesting dogs [9].

Rickettsia conorii is reported to infect dogs [24], but the only clinical signs observed in experimentally infected dogs were pain, erythema and edema at the inoculation site and regional lymphadenopathy [21]. Moreover, clinical disease, accompanied by seroconversion or PCR detection of $R c$ DNA has not been described in dogs from endemic regions. For this reason, the 
clinical significance of infection with $R c$, or other spotted fever group rickettsiae in dogs, is currently unknown. The very high seroprevalences detected in Spanish dogs would suggest frequent exposure to Rickettsia spp. or persistent low-grade infection with a rickettsial organism or organisms that cross react with $R c$ antigens by IFA testing. The possibility that $R c$ may cause a clinical disease in dogs is supported by the association between anemia and seroreactivity to $R c$ antigens found in this study. Further studies are needed to clarify the clinical and epidemiological importance of spotted fever group rickettsial infections of dogs in the Mediterranean basin.

According to our results, $\mathrm{Li}$ seroprevalence in Mallorca is 29.3\%, which is similar to a previous study (26\%) [37]. Unsurprisingly, statistically significant differences were found between seroprevalences in clinically healthy $(15 \%)$ and sick dogs $(49.3 \%)$ further supporting the importance of $L i$ infection as a cause of clinical disease in dogs in the Mediterranean basin. It is well known that the detection of $L i$ antibodies correlates with clinical disease in dogs with leishmaniasis [30, 37]. Furthermore, higher seroprevalences were found in dogs from Tarragona $(51.7 \%)$ and Barcelona $(65 \%)$ perhaps due to the fact that there were higher proportions of sick dogs compared to Mallorca in the samples obtained in these cities. In this study, $L i$ was the only vectorborne pathogen that was statistically associated with clinical disease in dogs in northeastern Spain.

The Ec seroprevalence in central Spain can range from $2.2 \%$ [31] to $19.2 \%$ [32] depending on the location and population studied. The total $E c$ seroprevalence by the IFA method described in this study in the northeast part of Spain was $16.7 \%$, which is in the higher range of the previous studies performed in central Spain [32]. An association was found between the detection of $R c$ and $E c$ antibodies; a result not unexpected due to the fact that both pathogens can be transmitted by the same tick, $R$. sanguineus.
This study provides the first serological evidence for canine exposure to $A p$ $(10.3 \%)$, or related species in dogs living in the three Mediterranean basin regions. Exposure appears to be more prevalent in Mallorca as compared to Barcelona and Tarragona. Canine anaplasmosis (formerly granulocytic ehrlichiosis) has been previously diagnosed serologically in Italy [15]. Recently, the first molecular evidence of $A p$ infection in a sick dog living in the south of Italy [22] and two sick dogs living in northern Greece [25] were reported. There is also one study that detected $A p$ DNA in blood samples from cattle in Sicily [13] and another study in which $A p$ antibodies were reported $(5.7 \%)$ in free-ranging jackals in Israel [44].

It is well known that $A p$ is transmitted by Ixodes ricinus ticks, which also transmit $B b$ in central European countries such as in central Italy [5], Bulgaria [4] and Switzerland [29]. In northern Spain (regions close to the atlantic ocean), there are reports of $A p$ infection in Ixodes ticks, in humans [27], in larvae of Neotrombicula autumnalis [10], in sheep where infection can result in abortions [12], in cattle with non-specific illness [20] and in wild small mammals and roe deer [26]. In the Mediterranean basin I. ricinus is rarely encountered [9]. Further evidence supporting infrequent exposure to the Ixodes species in the Mediterranean basin $[4,13]$ is the fact that Lyme disease is uncommonly reported in dogs or humans in this region. As described in this study, the overall $B b$ seroprevalence was only $0.6 \%$ and there was not a statistical association between $B b$ and $A p$ seroreactivity among the three study sites. No studies have reported $A p$ in $R$. sanguineus ticks; however, a recent study reported $A p$ DNA in $R$. bursa from Albania [4].

Dog sera from Mallorca recognized Ec antigens by IFA testing (17.6\%) that were not detected by a commercial diagnostic test (Snap 3DX) that uses Ec synthetic peptides as antigens (0\%) [2]. With one reported exception [34], this result differs 
from the serological results obtained using dog sera from Tarragona and Barcelona as well as the comparative IFA experience in the USA [2] and Israel [17]. In addition, the geometric mean Ec IFA titer was statistically much lower in Mallorca dogs than the geometric mean titers for dogs from Tarragona or Barcelona. Collectively, these findings could support the presence of a unique or new Ehrlichia species on the island of Mallorca. Anaplasma platys infection is common in dogs living in the Mediterranean basin in countries such as Spain [33], Greece and Italy [39]. However, since $A$. platys does not serologically cross-react with $E c$ [11], it is unlikely that our Ec IFA results are due to $A$. platys infection. Dogs from Mallorca and to a lesser extent Barcelona appear to be exposed to $A p$ or a closely related organism. Although some dogs had comparable IFA titers to both $E c$ and $A p$, many had higher titers (by a two-four-fold difference) to $A p$ and some dogs only had titers to $A p$, not $E c$. It is possible that infection with $A p$ or a related species induces IFA seroreactivity to $E c$ antigens in dogs on Mallorca that is not detected by the commercially available peptide ELISA used in this study. Another possibility could be that a species related to $E c$ is found on the island of Mallorca, and that this currently unrecognized Ehrlichia species originated or was introduced at some distant time point in the past. Molecular and cell-culture isolation techniques will be required to identify the Ehrlichia and Anaplasma organisms to which dogs on Mallorca are exposed.

Based upon serological evidence using both IFA and Snap 3DX testing, dogs from Tarragona and Barcelona are frequently exposed to $E c$. The statistical association between $E c$ exposure and $A p$ exposure could represent variability in the duration of infection, as observed in experimentally infected dogs [43] or the degree of serological cross reactivity among individual dogs when exposed to a common organism, i.e. another Ehrlichia or Anaplasma spp. or concurrent exposure to both Ehrlichia and Anaplasma species. Collectively, the above associations would seem to support transmission by the same means or same vector (tick).

In Spain, there is limited information describing $B h$ infection in humans [3] and only one study has been performed in cats with a seroprevalence of $29.6 \%$ [28]. In this study, the $B h$ seroprevalence was $16.8 \%$ in dogs from Spain. Two canine serosurveys carried out in Hawaii and the United Kingdom described $B h$ seroprevalences of $6.5 \%$ [7], and 3\% [1], respectively. A recent serosurvey from the southeastern USA describes seroprevalences of $10.1 \%$ in clinically healthy dogs and $27.2 \%$ in sick dogs with clinical signs compatible with a tick-flea vector borne disease [38]. In the present study, there was no difference found between the $B h$ antibody prevalences among clinically healthy and sick dogs. This discrepancy could be explained by regional differences in $B h$ virulence or differences in the dog populations studied. Sera in the US study were selected from sick dogs that were tested for exposure to other tick borne organisms, such as Rickettsia, Ehrlichia and Babesia [38]. In this study, all sick dogs were included, regardless of the type of illness. A recent study reported that seroreactive dogs to Bartonella were more likely to be lame or have arthritis-related lameness, nasal discharge or epistaxis, or splenomegaly [18]. A more focused study is needed to clarify if an association between $B h$ seroreactivity and illness exists in dogs from Spain.

In this study, exposure to $D i$ and $B v b$ was uncommon in dogs from northeastern Spain. Dirofilaria immitis infection is highly prevalent (up to 60\%) in dogs from the Canary Islands (Spain) [23] whereas in this study $D i$ antigen prevalence was only $0.6 \%$ as previously described in the Mediterranean basin [6]. The overall $B v b$ seroprevalence in this study was $1.07 \%$, with $1.3 \%$ in Mallorca, $0.86 \%$ in Tarragona and $0 \%$ in Barcelona. These seroprevalences are among the lowest canine seroprevalences described in the literature to date. Bartonella vinsonii 
(berkhoffii) seroprevalences range between $0-4.8 \%$ in French dogs to $65 \%$ in dogs from Sudan $^{1}$ [19]. Differences in seroprevalence are most likely related to differences in the dog population studied, geographical differences in vector exposure and potential differences in the serological methods employed.

In conclusion, this manuscript reports evidence of exposure of selected arthropodborne pathogens in this convenience sample of dogs in northeastern Spain. The study indicates that these dogs are frequently exposed to $R c, L i, E c, B h$ and $A p$. In contrast, there is infrequent exposure to $D i, B b$, and $B v b$ in dogs from the same geographical region. We also provide serological data that suggests the potential existence of a novel Ehrlichia species on the island of Mallorca.

\section{ACKNOWLEDGMENTS}

We thank participating veterinarians for the collection of samples from the dogs in this study, members of the Vector Borne Diseases Laboratory at North Carolina State University for helpful discussions, and Alheli Rodríguez from Universitat Autònoma de Barcelona for her help in shipping samples to North Carolina State University for evaluation.

Dr Solano-Gallego was supported financially by a grant from La Caixa bank (Barcelona, Spain) and her research was supported by the State of North Carolina. We also thank IDEXX Laboratories for the donation of the Canine SNAP ${ }^{\circledR} 3 \mathrm{Dx}^{\mathrm{TM}}$ Test kits used in this study.

\section{REFERENCES}

[1] Barnes A., Bell S.C., Isherwood D.R., Bennet M., Carter S.D., Evidence of Bartonella henselae infection in cats and dogs in the

1 Davoust B., Drancourt M., Boni M., Signot J., Roux V., Raoult D., Survey of seroprevalence of Bartonella vinsonii, Ehrlichia canis and Coxiella burnetti in dogs in southeast France, French Guyana, Martinique, Senegal, Ivory Coast and Sudan, EUWOG-ASR Joint meeting, Marseille, 1999.
United Kingdom, Vet. Rec. 147 (2000) 673677.

[2] Belanger M., Sorenson H.L., France M.K., Bowie M.V., Barbet A.F., Breitschwerdt E.B., Alleman A.R., Comparison of serological detection methods for diagnosis of Ehrlichia canis infections in dogs, J. Clin. Microbiol. 40 (2002) 3506-3508.

[3] Blanco J.R., Oteo J.A., Martinez V., Ramalle E., Garcia A., Ibarra V., Rosel L., Seroepidemiology of Bartonella henselae infection in HIV-infected patients, Enferm. Infecc. Microbiol. Clin. 17 (1999) 434-438 (in Spanish).

[4] Christova I., van De Pol J., Yazar S., Velo E., Schouls L., Identification of Borrelia burgdorferi sensu lato, Anaplasma and Ehrlichia species, and spotted fever group Rickettsiae in ticks from Southeastern Europe, Eur. J. Clin. Microbiol. Infect. Dis. 22 (2003) 535-542.

[5] Cinco M., Padovan D., Murgia R., Maroli M., Frusteri L., Heldtander M., Johansson K.E., Engvall E.O., Coexistence of Ehrlichia phagocytophila and Borrelia burgdorferi sensu lato in Ixodes ricinus ticks from Italy as determined by $16 \mathrm{~S}$ rRNA gene sequencing, J. Clin. Microbiol. 35 (1997) 3365-3366.

[6] Cringoli G., Rinaldi L., Veneziano V., Capelli G., A prevalence survey and risk analysis of filariosis in dogs from the Mt. Vesuvius area of southern Italy, Vet. Parasitol. 102 (2001) 243-252.

[7] Demers D.M., Bass J.W., Vincent J.M., Person D.A., Noyes D.K., Staege C.M., Samlaska C.P., Lockwood N.H., Regnery R.L., Anderson B.E., Cat-scratch disease in Hawaii: etiology and seroepidemiology, J. Pediatr. 127 (1995) 23-26.

[8] Espejo-Arenas E., Font-Creus B., AlegreSegura M.D., Segura-Porta F., Bella-Cueto F., Seroepidemiological survey of Mediterranean spotted fever in an endemic area (Valles Occidental, Barcelona, Spain), Trop. Geogr. Med. 42 (1990) 212-216.

[9] Estrada-Pena A., Osacar J.J., Gortazar C., Calvete C., Lucientes J., An account of the ticks of the northeastern of Spain (Acarina: Ixodidae), Ann. Parasitol. Hum. Comp. 67 (1992) 42-49.

[10] Fernandez-Soto P., Perez-Sanchez R., EncinasGrandes A., Molecular detection of Ehrlichia phagocytophila genogroup organisms in larvae of Neotrombicula autumnalis (Acari: Trombiculidae) captured in Spain, J. Parasitol. 87 (2001) 1482-1483.

[11] French T.W., Harvey J.W., Serologic diagnosis of infectious cyclic thrombocytopenia in 
dogs using an indirect fluorescent antibody test, Am. J. Vet. Res. 44 (1983) 2407-2411.

[12] Garcia-Perez A.L., Barandika J., Oporto B., Povedano I., Juste R.A., Anaplasma phagocytophila as an abortifacient agent in sheep farms from northern Spain, Ann. NY Acad. Sci. 990 (2003) 429-432.

[13] Georges K., Loria G.R., Riili S., Greco A., Caracappa S., Jongejan F., Sparagano O., Detection of haemoparasites in cattle by reverse line blot hybridisation with a note on the distribution of ticks in Sicily, Vet. Parasitol. 31 (2001) 273-286.

[14] Goodman J.L., Nelson C., Vitale B., Madigan J.E., Dumler J.S., Kurtti T.J., Munderloh U.G., Direct cultivation of the causative agent of human granulocytic ehrlichiosis, N. Engl. J. Med. 334 (1996) 209-215.

[15] Gravino A.E., De Caprariis D., Manna L., Cerundolo R., Sagazio P., Buonavoglia C., Preliminary report of infection in dogs related to Ehrlichia equi: description of three cases, New Microbiol. 20 (1997) 361-363.

[16] Guberman D., Mumcuoglu K.Y., Keysary A., Ioffe-Uspensky I., Miller J., Galun R., Prevalence of spotted fever group Rickettsiae in ticks from southern Israel, J. Med. Entomol. 33 (1996) 979-982.

[17] Harrus S., Alleman A.R., Bark H., Mahan S.M., Waner T., Comparison of three enzymelinked immunosorbant assays with the indirect immunofluorescent antibody test for the diagnosis of canine infection with Ehrlichia canis, Vet. Microbiol. 86 (2002) 361-368.

[18] Henn J.B., Liu C.H., Kasten R.W., VanHorn B.A., Beckett L.A., Kass P.H., Chomel B.B., Seroprevalence of antibodies against Bartonella species and evaluation of risk factors and clinical signs associated with seropositivity in dogs, Am. J. Vet. Res. 66 (2005) 688-694.

[19] Honadel T.E., Chomel B.B., Yamamoto K., Chang C., Farver T.B., Seroepidemiology of Bartonella vinsonii subsp. berkhoffii exposure among healthy dogs, J. Am. Vet. Med. Assoc. 219 (2001) 480-484.

[20] Juste R.A., Scott G.R., PaxtonE.A., Gelabert J.L., Jimenez S., Presence of Cytoecetes phagocytophila in an atypical disease of cattle in Spain, Vet. Rec. 124 (1989) 636.

[21] Kelly P.J., Matthewman L.A., Mason P.R., Courtney S., Katsande C., Rukwava J., Experimental infection of dogs with a Zimbabwean strain of Rickettsia conorii, J. Trop. Med. Hyg. 95 (1992) 322-326.

[22] Manna L., Alberti A., Pavone L.M., Scibelli A., Staiano N., Gravino A.E., First molecular characterization of a granulocytic Ehrlichia strain isolated from a dog in South Italy, Vet. J. 167 (2004) 224-227.

[23] Montoya J.A., Morales M., Ferrer O., Molina J.M., Corbera J.A., The prevalence of Dirofilaria immitis in Gran Canaria, Canary Islands, Spain (1994-1996), Vet. Parasitol. 75 (1998) 221-226.

[24] Mumcuoglu K.Y., Frish K., Sarov B., Manor E., Gross E., Gat Z., Galun R., Ecological studies on the brown dog tick Rhipicephalus sanguineus (Acari: Ixodidae) in southern Israel and its relationship to spotted fever group Rickettsiae, J. Med. Entomol. 30 (1993) 114-121.

[25] Mylonakis M.E., Koutinas A.F., Breitschwerdt E.B., Hegarty B.C., Billinis C.D., Leontides L.W. Kontos V.S., Chronic canine ehrlichiosis (Ehrlichia canis): a retrospective study of 19 natural cases, J. Am. Anim. Hosp. Assoc. 40 (2004) 174-184.

[26] Oporto B., Gil H., Barral M., Hurtado A., Juste R.A., Garcia-Perez A.L., A survey on Anaplasma phagocytophila in wild small mammals and roe deer (Capreolus capreolus) in northern Spain, Ann. NY Acad. Sci. 990 (2003) 98-102.

[27] Oteo J.A., Gil H., Barral M., Perez A., Jimenez S., Blanco J.R., Martinez de Artola V., GarciaPerez A., Juste R.A., Presence of granulocytic Ehrlichia in ticks and serological evidence of human infection in La Rioja, Spain, Epidemiol. Infect. 127 (2001) 353-358.

[28] Pons I., Sanfeliu I., Quesada M., Anton E., Sampere M., Font B., Pla J., Segura F., Prevalence of Bartonella henselae in cats in Catalonia, Spain, Am. J. Trop. Med. Hyg. 72 (2005) 453-457.

[29] Pusterla N., Leutenegger C.M., Huder J.B., Weber R., Braun U., Lutz H., Evidence of the human granulocytic ehrlichiosis agent in Ixodes ricinus ticks in Switzerland, J. Clin. Microbiol. 37 (1999) 1332-1334.

[30] Quinnell R.J., Courtenay O., Davidson S., Garcez L., Lambson B., Ramos P., Shaw J.J., Shaw M.A., Dye C., Detection of Leishmania infantum by PCR, serology and cellular immune response in a cohort study of Brazilian dogs, Parasitology 122 (2001) 253-261.

[31] Sainz A., Tesouro M.A., Rodriguez F., Mayoral I., Mazzucchelli F., Seroprevalence of Ehrlichia canis infections in police dogs in Spain, Prev. Vet. Med. 23 (1995) 179-182.

[32] Sainz A., Delgado S., Amusategui I., Tesouro M.A., Carmenes P., Seroprevalence of canine ehrlichiosis in Castilla-Leon (north-west Spain), Prev. Vet. Med. 29 (1996) 1-7. 
[33] Sainz A., Amusategui I., Tesouro M.A., Ehrlichia platys infection and disease in dogs in Spain, J. Vet. Diagn. Invest. 11 (1999) 382384.

[34] Seaman R.L., Kania S.A., Hegarty B.C., Legendre A.M., Breitschwerdt E.B., Comparison of results for serologic testing and a polymerase chain reaction assay to determine the prevalence of stray dogs in eastern Tennessee seropositive to Ehrlichia canis, Am. J. Vet. Res. 65 (2004) 1200-1203.

[35] Segura-Porta F., Diestre-Ortin G., OrtunoRomero A., Sanfeliu-Sala I., Font-Creus B., Munoz-Espin T., de Antonio E.M., CasalFabrega J., Prevalence of antibodies to spotted fever group Rickettsiae in human beings and dogs from and endemic area of Mediterranean spotted fever in Catalonia, Spain, Eur. J. Epidemiol. 14 (1998) 395-398.

[36] Shaw S.E., Day M.J., Birtles R.J., Breitschwerdt E.B., Tick-borne infectious diseases of dogs, Trends Parasitol. 17 (2001) 74-80.

[37] Solano-Gallego L., Morell P., Arboix M., Alberola J., Ferrer L., Prevalence of Leishmania infantum infection in dogs living in an area of canine leishmaniasis endemicity using PCR on several tissues and serology, J. Clin. Microbiol. 39 (2001) 560-563.

[38] Solano-Gallego L., Bradley J., Hegarty B., Sigmon B., Breitschwerdt E.B., Bartonella henselae IgG antibodies are prevalent in dogs from southeastern USA, Vet. Res. 35 (2004) 585-595.
[39] Sparagano O.A., de Vos A.P., Paoletti B., Camma C., de Santis P., Otranto D., Giangaspero A., Molecular detection of Anaplasma platys in dogs using polymerase chain reaction and reverse line blot hybridization, J. Vet. Diagn. Invest. 15 (2003) 527-534.

[40] Suksawat J., Hegarty B.C., Breitschwerdt E.B., Seroprevalence of Ehrlichia canis, Ehrlichia equi, and Ehrlichia risticii in sick dogs from North Carolina and Virginia, J. Vet. Intern. Med. 14 (2000) 50-55.

[41] Tringali G., Intonazzo V., Perna A.M., Mansueto S., Vitale G., Walker D.H., Epidemiology of boutonneuse fever in western Sicily. Distribution and prevalence of spotted fever group rickettsial infection in dog ticks (Rhipicephalus sanguineus), Am. J. Epidemiol. 123 (1986) 721-727.

[42] Trotz-Williams L.A., Trees A.J., Systematic review of the distribution of the major vectorborne parasitic infections in dogs and cats in Europe, Vet. Rec. 152 (2003) 97-105.

[43] Waner T., Strenger C., Keysary A., Harrus S., Kinetics of serologic cross-reactions between Ehrlichia canis and the Ehrlichia phagocytophila genogroups in experimental E. canis infection in dogs, Vet. Immunol. Immunopathol. 66 (1998) 237-243.

[44] Waner T., Baneth G., Strenger C., Keysary A., King R., Harrus S., Antibodies reactive with Ehrlichia canis, Ehrlichia phagocytophila genogroup antigens and the spotted fever group rickettsial antigens, in free-ranging jackals (Canis aureus syriacus) from Israel, Vet. Parasitol. 82 (1999) 121-128. 